\title{
Massed and spaced training build up different components of long-term habituation in the crab Chasmagnathus
}

\author{
MARÍA EUGENIA PEDREIRA, ARTURO ROMANO, DANIEL TOMSIC, \\ MARIANA LOZADA, and HÉCTOR MALDONADO \\ Universidad de Buenos Aires, Buenos Aires, Argentina
}

\begin{abstract}
The crab Chasmagnathus granulatus reacts to a shadow passing overhead with an escape response that habituates after 30 trials and for 5 days at least. The effect of a wide range of different intertrial intervals (ITIs) $(0,9,27,45,81,135$, and $171 \mathrm{sec})$ on the Chasmagnathus long-term habituation (LTH) was evaluated at $24 \mathrm{~h}$. Memory retention was estimated separately at two phases of a six-trial testing session: at first trial (the initial testing phase) and at the subsequent block of five trials (the retraining phase). A training of 30 trials with an ITI equal to or longer than $27 \mathrm{sec}$ induced LTH at both testing phases, however, with a 0 - or a 9-sec ITI, training wholly failed to build up LTH. When the number of trials was increased, a massed training (ITI $=0$ or $9 \mathrm{sec}$ ) induced LTH at retraining but not at initial testing. Thus, massed training produces LTH only at retraining, whereas spaced training (ITI $\geq 27 \mathrm{sec}$ ) produces LTH at both initial phase and retraining. An ITI shift from training to testing diminished or abolished retention at retraining regardless of the direction of the shift, thus suggesting that crabs acquire a memory of the trial-spacing at training. According to these results, it is postulated that LTH consists of two memory components: one produced by spaced training and expressed at both initial testing and retraining, and one yielded by massed training and expressed only at retraining. The possibility that the two components of LTH were differentially affected by cycloxemide and context shift is discussed.
\end{abstract}

Different experiments with different animal species have repeatedly shown an apparently universal behavioral property in associative memory formation-namely, that spaced training produces stronger, longer lasting memory than does massed training (Carew, Pinsker, \& Kandel, 1972; Frost, Castellucci, Hawkin, \& Kandel, 1985; Hintzman, 1974). Lately, there has been renewed attention to this subject. Rationale for such an upsurge of interest is that massed and spaced training appear in several instances to be subserving functionally independent memory components of the same mnemonic process. For example, consolidated memory after olfactory learning in Drosophila consists of two components: a long-term memory that is cycloheximide-sensitive and depends on spaced training, and an anesthesia-resistant memory that is cycloheximideinsensitive and does not require spaced training (Tully, Preat, Boyton, \& Del Vecchio, 1994). Likewise, studies on conditioning of the proboscis extension response in the honeybee have shown disruption by cycloheximide with a long interval between training trials (Menzel, 1996) but

This work was supported by Fundacion Antorchas and by Grant EX212 from the Universidad de Buenos Aires. The authors thank Angel Vidal for technical assistance. Correspondence should be addressed to H. Maldonado, Depto. de Biología, Ciudad Universitaria, Pabellón 2, 1429 Buenos Aires, Argentina (e-mail: hector@biolobg.fcen.uba.ar).

-Accepted by previous editor, Robert A. Rescorla not with short ones (Menzel, Gaio, Gerberding, Nemrava, \& Wittstock, 1993).

The crab Chasmagnathus granulatus reacts to the iterative presentation of a shadow passing overhead with an escape response that habituates quickly and for at least 5 days (Brunner \& Maldonado, 1988; Lozada, Romano, \& Maldonado, 1990; Pedreira, Dimant, Tomsic, QuesadaAllue, \& Maldonado, 1995). The robust long-term habituation (LTH) is assessed by the difference between performances of trained and untrained animals during a six-trial testing session carried out after a long rest interval. The systemic administration of diverse amnestic agents (cycloheximide, actinomicyn-D, ethanol, or a PKA inhibitor) or facilitatory agents as PKA activators (Pedreira, Dimant, \& Maldonado, 1996; Pedreira et al., 1995; Romano, Delorenzi, Pedreira, Tomsic, \& Maldonado, 1996; Romano, Locatelli, Delorenzi, Pedreira, \& Maldonado, 1996; Saraco \& Maldonado, 1995) impacted mainly on the initial testing phase (i.e., the first testing trial), with weaker effect on the late phase. These results hint at the possibility that two memory components would be involved in the crab's LTH-namely, one component that is mainly expressed at an initial phase of testing and a second one at a late phase. Therefore, apart from ascertaining the dependence of LTH on stimulus spacing, the main purpose of the present study was to explore a likely relation between length of the intertrial interval (ITI) during the 
Table 1

General Experimental Protocol

\begin{tabular}{|c|c|c|c|c|}
\hline \multicolumn{3}{|c|}{ Training Session } & \multicolumn{2}{|c|}{ Testing Session } \\
\hline $\begin{array}{l}\text { Pretraining } \\
\text { Phase }\end{array}$ & $\begin{array}{l}\text { Contextual } \\
\text { Phase }\end{array}$ & $\begin{array}{l}\text { Stimulation } \\
\text { Phase }\end{array}$ & $\begin{array}{l}\text { Contextual } \\
\text { Phase }\end{array}$ & $\begin{array}{l}\text { Stimulation } \\
\text { Phase }\end{array}$ \\
\hline \multicolumn{5}{|c|}{ Trained (TR) Group } \\
\hline $\begin{array}{l}2 \text { trials } \\
(\mathrm{ITI}=9 \mathrm{sec})\end{array}$ & $X \min$ & $\begin{array}{l}5,10,15,30,60 \\
120, \text { or } 300 \text { trials }\end{array}$ & $15 \mathrm{~min}$ & $\begin{array}{l}\text { Initial phase, Trial 1; } \\
\text { Retraining, Trials } 2-6\end{array}$ \\
\hline \multicolumn{5}{|c|}{ Control (CT) Group } \\
\hline $\begin{array}{l}2 \text { trials } \\
(\text { ITI }=9 \mathrm{sec})\end{array}$ & $X \min$ & & $15 \mathrm{~min}$ & $\begin{array}{l}\text { Initial phase, Trial 1; } \\
\text { Retraining, Trials 2-6 }\end{array}$ \\
\hline
\end{tabular}

Note-The testing session took place $24 \mathrm{~h}$ after the training session.

training session (habituating session) and two putative memory components of LTH.

Finally, an additional purpose of the present work was to investigate to what extent LTH depends on the agreement between training and testing stimulus spacing, given that previous results of our laboratory have suggested that memory of stimulus timing is involved in the Chasmagnathus LTH (Lozada, 1993).

\section{METHOD}

\begin{abstract}
Animals
The animals were adult male Chasmagnathus crabs, $2.6-2.9 \mathrm{~cm}$ across the carapace, weighing around $17 \mathrm{~g}$, collected from water less than $1 \mathrm{~m}$ deep in the rias (narrow coastal inlets) of San Clemente del Tuyu', Argentina, and transported to the laboratory, where they were lodged in plastic tanks $(35 \times 48 \times 27 \mathrm{~cm})$ filled to $2 \mathrm{~cm}$ in depth with diluted marine water to a density of 20 crabs per tank. Water used in the tanks and other containers during experiments was prepared using hw-Marinex (Winex-Germany; salinity 10\%-14\%, $\mathrm{pH}$ 7.4-7.6). The holding room was maintained on a 12-h light:dark cycle (lights on $0700-1900 \mathrm{~h}$ ). The animals were fed rabbit pellets (Nutrientes S.A., Argentina) every 3 days. After feeding, the water was changed. Temperature of both holding and experimental rooms was maintained within a range of $22^{\circ}-24^{\circ} \mathrm{C}$. Experiments were carried out within the first week after the animal's arrival, from January to August. Each crab was used in only one experiment.
\end{abstract}

\section{Apparatus}

The apparatus is described in detail elsewhere (Romano, Lozada, \& Maldonado, 1990). Briefly, the experimental unit was the actometer - a bowl-shaped plastic container with a steep concave wall and a circular central flat floor $10 \mathrm{~cm}$ in diameter, covered to a depth of $0.5 \mathrm{~cm}$ with marine water. The crab was lodged in the container, which was suspended by three strings from an upper wooden framework $(23 \times 23 \times 30 \mathrm{~cm})$ and illuminated by a 10 -W lamp placed $30 \mathrm{~cm}$ above the animal. A motor moved horizontally an opaque rectangular screen (a strip of $25 \times 7.5 \mathrm{~cm}$ ) over the animal and across the upper surface of the framework, cyclically from left to right, and vice versa. A cycle of movement lasted nearly $4 \mathrm{sec}$. Screen displacements provoked the crab's running response and consequent container oscillations. A stylus was centrally cemented to the bottom of the container and connected to a piezoelectric transducer. Container oscillations induced electrical signals proportional to the velocity of the oscillations through the transducer. Such signals were amplified, integrated during the recording time $(9 \mathrm{sec})$, and translated into numerical units ranging from 0 to 1,530 before being processed by a computer. Thus, the scores were proportionally correlated to the velocity and number of oscillations recorded during $9 \mathrm{sec}$. The experimental room had 40 actometers, isolated from each other by parti- tions. To avoid unobserved malfunctioning, the actometers were periodically calibrated against one another by throwing small lead balls from the upper border of the framework to the center of the container and recording the score for $9 \mathrm{sec}$. A computer was employed to program trial sequences, trial duration, and ITIs, as well as to monitor experimental events.

\section{Experimental Procedure and Design}

Each crab was moved from the holding room to one actometer in the experimental room. All experiments included a training session and a testing session, separated by a 24 -h interval. The crabs were individually housed during the entire intersession interval in plastic containers, covered to a depth of $0.5 \mathrm{~cm}$ with water and kept inside dimly lighted drawers. Each trial consisted of two successive cycles of screen movement without a rest interval between cycles. Since each cycle lasted nearly $4 \mathrm{sec}$, the total trial time was around $9 \mathrm{sec}$. The trial was constituted in this way for two purposes: (1) to obtain a more conspicuous response for each trial, thus ensuring strong oscillations of the container per trial, and (2) to make certain that the passing screen entered the crab's visual field twice from two opposite sides during each trial, thus ensuring that the animals were similarly stimulated regardless of their positions inside the container. The crab's activity was recorded during the entire trial time

Each experiment included one control (CT) group that stayed in the actometers during the entire training session but without being trained, and one or more trained (TR) groups. All animals were given a pretraining phase consisting of two trials with a 9-sec ITI. The crabs were assigned to each group, taking into account their response levels at pretraining, in such a way that a similar mean baseline of reactivity was obtained for the different groups of the same experiment. Apart from pretraining, two other phases were present in the training session (Table 1): the stimulation phase in which TR crabs were stimulated with the passing screen, and the contextual phase in which the crabs stayed in the apparatus without being trained. During the stimulation phase, trained groups received a fixed number of trials, separated by an ITI of $0,9,27,45,81,135$, or $171 \mathrm{sec}$, such that the time spent during this phase for the various TR groups differed as function of the number of trials or the ITI used. Therefore, a contextual phase, between pretraining and stimulation, was included in the training session to ensure that all the TR groups of an experiment spent a total time in the actometer equivalent in length to the time spent for the corresponding control group. The control group had no stimulation phase; therefore, after pretraining, the training session was entirely the contextual phase. The testing session was the same for all groups, and it consisted of a 15-min contextual phase and a stimulation phase with six trials separated by one of the above ITIs. The design of each experiment is fully described in connection with the presentation of results. Throughout this study, each experimental group consisted of 20 animals.

Before the animals were placed in the actometers to start an experiment, they underwent a selection test: Each crab was turned on its back, and only the animals that immediately returned to their nor- 
Table 2

Protocol for the First Series of Experiments

\begin{tabular}{ccccccc}
\hline & & & & \multicolumn{2}{c}{ Training Session } & \\
\cline { 6 - 7 } Experiment & Group & Training & Training & Contextual & Stimulation & Testing \\
& Name & Trials & ITI (sec) & Phase (min) & Phase (min) & ITI (sec) \\
\hline 1 & CT-171 & - & - & 90 & 0 & 171 \\
2 & $171-171$ & 30 & 171 & 0 & 90 & 171 \\
2 & CT-171 & - & - & 45 & 0 & 171 \\
3 & $171-171$ & 15 & 171 & 0 & 45 & 171 \\
& CT-171 & - & & 30 & 0 & 171 \\
4 & $171-171$ & 10 & 171 & 0 & 30 & 171 \\
& CT-171 & - & - & 15 & 0 & 171 \\
& $171-171$ & 5 & 171 & 0 & 15 & 171 \\
\hline
\end{tabular}

mal position were used. The rationale behind this selection was that crabs with a slow righting reaction show a low responsiveness to a large diversity of stimuli, and, at a later time, they usually present unhealthy symptoms. No more than $10 \%$ of the tested crabs were eliminated.

The crabs' baseline of responsiveness to the passing screen, on the basis of the data from pretraining, proved remarkably consistent up to 10 days after arrival; however, on occasion, the animals coming from different capture efforts presented differences in response level. Therefore, only the crabs belonging to the same capture were used in each experiment. The groups of each experiment were run simultaneously. In the Results section, it is indicated when the crabs came from different captures.

The response level of the CT group at the first testing trial was sometimes considerably different from that at the first trial of pretraining. However, the difference failed to reach the significance level, and no consistent increasing or decreasing tendency was found across experiments.

\section{Data Analysis}

Long-term memory was assessed by focusing the data analysis on testing scores. Rescorla (1988) convincingly argued in favor of using this sort of analysis instead of a paired training-testing comparison, stressing the need to clearly distinguish between time of input (training session) and time of assessment (testing session). This view is well justified in the present case, since it has been demonstrated that LTH in the crab is independent of the escape response level at training (Tomsic, Maldonado, \& Rakitin, 1991), a result consistent with similar findings in other animals (Applewhite, Gardner, \& Lapan, 1969; Peeke \& Veno, 1976).

In all previous experiments at our laboratory, without exception, a significant difference ( $t$ test, $\alpha=.05$ ) between testing scores from a CT group and a TR group was disclosed $24 \mathrm{~h}$ after training, provided that each group consisted of 20 or more crabs and that the crabs were given 15-30 training trials separated by a 171-sec ITI. Such experimental protocol is considered to be a strong training protocol in contrast to that of 10 or fewer training trials, which invariably fails to induce LTH. Accordingly, predictions are for a significant difference at testing in each CT-TR comparison, except when memory was impaired because the treatment introduced some change in the parametrical conditions of the strong training protocol. Therefore, testing results of this study were analyzed by performing plannedcomparisons, weighted-means analyses of variances (ANOVAs) with $\alpha=.05$ (Howell, 1987; Rosenthal $\&$ Rosnow, 1985) between the CT group and each TR group.

Concerning the analysis of results from testing, a distinction between the first testing trial and the subsequent block of five trials (the retraining phase) is made throughout the study. This distinction seems to be pertinent since the response level at retraining, unlike that at first trial, could be influenced by the recordatory effect of the first trial (Campbell \& Jaynes, 1966) and by the congruity between training and testing trial spacing. In addition, most of the experiments on LTH show that the escape response level at the first trial (or at the first two-trial block) of testing appears to be much more sensitive to changes in amount of training (Tomsic, Massoni, \& Maldonado, 1993), as well as to amnestic or hypermnestic agents (e.g., Pedreira et al., 1996; Pedreira et al., 1995; Romano, Delorenzi, et al., 1996; Romano, Lucatelli, et al., 1996; Saraco \& Maldonado, 1995). Therefore, comparisons on testing results were accomplished separately on each phase of testing--that is, on the first trial scores and on the data from the subsequent five trials.

\section{Definitions}

Short-term habituation refers to the response decrement within a training session. Long-term habituation (LTH) refers to a retention of the response decrement demonstrated in the testing session. Intertrial interval (ITI) refers to the rest interval between trials. Initial testing phase refers to the first testing trial. Retraining phase refers to the last five trials of the testing session (average of accumulative scores for the last five trials). Strong training protocol designates an experimental protocol that includes $15-30$ training trials with $171-\mathrm{sec}$ ITIs during training session. Weak training protocol refers to an experimental protocol that includes 10 or fewer trials. Note that both protocols had a testing session of six trials with the same ITI.

\section{RESULTS}

\section{First Series of Experiments}

Robust LTH induced by the strong training protocol is exhibited at both testing phases. The $171-\mathrm{sec}$ trial spacing has been used extensively in our laboratory (e.g., Lozada et al., 1990; Pedreira et al., 1995). The aim of the present section was to evaluate the effect of different numbers of training trials with such an ITI on the response level both at the first testing trial and at the retraining phase. A succession of four different experiments with the animals coming from different captures was conducted (Table 2). Each experiment included one control group and one trained group that received $30,15,10$, or 5 trials in the training session, with an ITI of $171 \mathrm{sec}$ in both training and testing. Each control group is termed CT-171 and each trained group, 171-171.

Results are presented in Figure 1. A $t$ test on data from both the 30- and the 15-trial training experiment (Figures $1 \mathrm{~A}$ and $1 \mathrm{~B}$ ) revealed a significant difference for CT versus TR corresponding to the first testing trial $[F(1,38)=$ $9.0, p<.005$, and $F(1,38)=7.4, p<.01$, respectively] and to the retraining phase $[F(1,38)=14.0, p<.001$, and 
A)

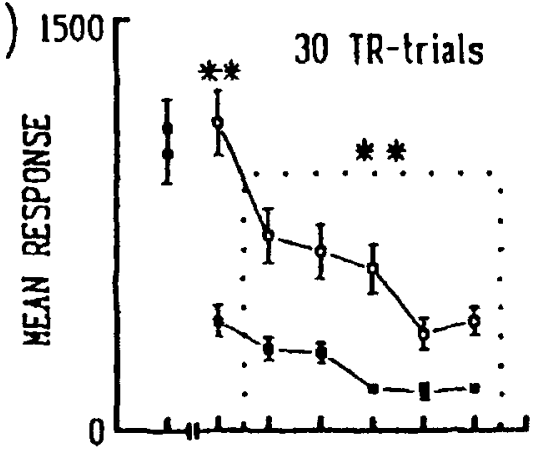

C)

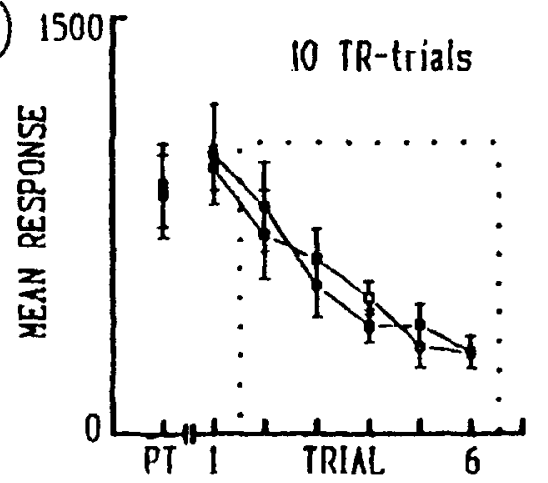

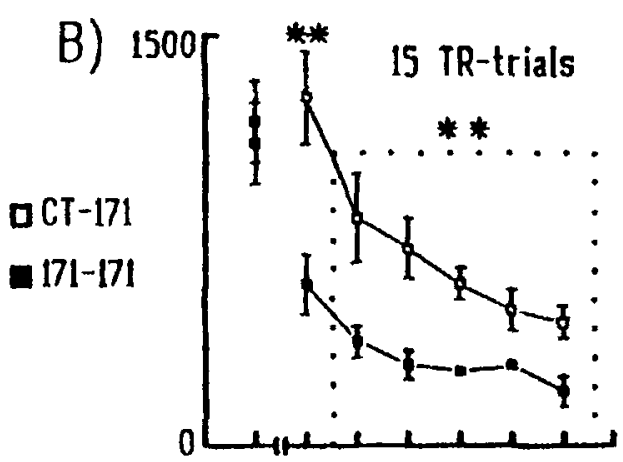

D)

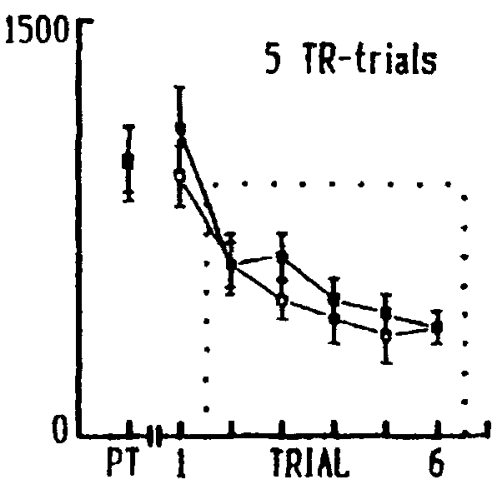

Figure 1. Effect of different number of training trials, with the same intertrial interval (171 sec), on LTH. Graphs A-C: Results at testing. (A) First experiment, 30 training trials; (B) 15 training trials; (C) 10 training trials; (D) 5 training trials. Intertrial interval = 171 sec at both training and testing. Open squares for CT groups. Black squares for TR groups. Ordinate: mean testing response; a bar stands for SEM. Abscissa: 6 testing trials. PT: first pretraining trial. A dashed line stands for the retraining phase. ${ }^{* *} p<.025$.

$F(1,38)=12.5, p<.001$, respectively]. In contrast, no significant difference was found at any testing phase for either 10-trial or 5-trial training (Figures $1 \mathrm{C}$ and 1D).

Thus, focusing the data analysis on both the initial and the retraining phases, an invariant result from our laboratory was confirmed: LTH is induced only when crabs are given 15-30 training trials- that is, when the strong training protocol is used. It is noteworthy, however, that, apart from the number of training trials, other parametrical conditions define the protocol-specifically, trial spacing (171 sec), congruity between training and testing ITI, and the length of both contextual phase and stimulation phase during the training session of the trained groups (e.g., $15 \mathrm{~min}$ and around $90 \mathrm{~min}$, respectively, when 30 training trials are given).

The following series of experiments were almed at ascertaining to what extent changes in such parameters influence LTH when the number of trials at training is kept constant (30 trials).

\section{Second Series of Experiments}

LTH at the first testing trial depends on length of the intertrial interval. The purpose of the experiments in this section was to evaluate if a training ITI less than
$171 \mathrm{sec}$ (i.e., 9, 27, or $81 \mathrm{sec}$ ) is able to induce LTH. Another purpose was to test whether congruity between training and testing ITIs is required to ensure retention. Therefore, each experiment (Table 3 ) comprised one control group and three trained groups that were given 30 training trials separated by a 9-, 27-, or 171-sec ITI; the groups were tested with a 9-sec ITI (Experiment 1), a 27-sec ITI (Experiment 2), and an 81 -sec ITI (Experiment 3). The training session lasted $45 \mathrm{~min}$ in the four groups of each experiment, and, as a consequence, the length of the training contextual and stimulation phases was different for each group (Table 3).

Results are displayed in Figures 2A, 2B, and 2C. In each panel of a given experiment, the trial-response curve of CT is shown together with that of each TR. An inspection of Figure 2 focused on CT performances at testing (i.e., CT9, CT-27, and CT-81) suggests that the patterns of the three curves are similar, although three different ITIs were used. This finding is not at variance with the generally accepted view that shorter ITIs result in more rapid and pronounced short-term (within-session) habituation (Thompson, Groves, Teyler, \& Roemer, 1973), since the ITIs effect in Chasmagnathus becomes apparent only when the response level reaches the asymptote-that is, generally after 
Table 3

Protocol for the Second Series of Experiments

\begin{tabular}{|c|c|c|c|c|c|c|}
\hline \multirow[b]{2}{*}{ Experiment } & \multirow[b]{2}{*}{$\begin{array}{l}\text { Group } \\
\text { Name }\end{array}$} & \multirow[b]{2}{*}{$\begin{array}{l}\text { Training } \\
\text { Trials } \\
\end{array}$} & \multirow[b]{2}{*}{$\begin{array}{l}\text { Training } \\
\text { ITI (sec) }\end{array}$} & \multicolumn{2}{|c|}{ Training Session ( $45 \mathrm{~min})$} & \multirow[b]{2}{*}{$\begin{array}{c}\text { Testing } \\
\text { ITI (sec) }\end{array}$} \\
\hline & & & & $\begin{array}{r}\text { Contextual } \\
\text { Phase (min) } \\
\end{array}$ & $\begin{array}{l}\text { Stimulation } \\
\text { Phase (min) }\end{array}$ & \\
\hline \multirow[t]{4}{*}{1} & CT-9 & - & - & 45 & 0 & 9 \\
\hline & $9-9$ & 30 & 9 & 36 & 9 & 9 \\
\hline & $27-9$ & 30 & 27 & 27 & 18 & 9 \\
\hline & $81-9$ & 30 & 81 & 0 & 45 & 9 \\
\hline \multirow[t]{4}{*}{2} & CT-27 & - & - & 45 & 0 & 27 \\
\hline & $9-27$ & 30 & 9 & 36 & 9 & 27 \\
\hline & $27-27$ & 30 & 27 & 27 & 18 & 27 \\
\hline & $81-27$ & 30 & 81 & 0 & 45 & 27 \\
\hline \multirow[t]{4}{*}{3} & CT-81 & - & - & 45 & 0 & 81 \\
\hline & $9-81$ & 30 & 9 & 36 & 9 & 81 \\
\hline & $27-81$ & 30 & 27 & 27 & 18 & 81 \\
\hline & $81-81$ & 30 & 81 & 0 & 45 & 81 \\
\hline
\end{tabular}

Trial 6 (Lozada, 1993). It is worth noting that response levels at the first pretraining trial (PT, Figure 2) were very similar for all the groups, which was an expected result since the crabs of the three experiments came from the same capture.

Figure 2A (Experiment 1) presents the trial-response curves corresponding to the testing session of each trained group compared with that of the CT-9 group. Planned comparisons showed significant difference only for CT-9 versus $27-9$ and CT-9 versus $81-9$ at the first testing trial $[F \mathrm{~s}(1,76)=4.5$ and 4.8 , respectively, $p \mathrm{~s} \leq .05]$. No significant difference was found in any contrast when results of the retraining phase were studied. The analysis of data of Experiment 2 (Figure 2B) corresponding to first testing total gave results similar to those of Experiment 1 -that is, significant differences were found only for CT-27 versus $27-27$ and CT- 27 versus $81-27[F(1,76)=5.6, p<.05$, and $F(1,76)=6.8, p \leq .01$, respectively]. Concerning the retraining phase, no significant difference was found for CT versus 9-27 nor for CT versus 81-27, but the difference for CT-27 versus 27-27 fell just short of statistical significance $[F(1,76)=3.5, .06>p>.05]$; in a replication of this experiment, these groups differed reliably at retraining. Finally, the analysis of data corresponding to groups trained with an 81-sec ITI (Figure 2C, Experiment 3) revealed a significant difference for both CT-81 versus $27-81$ and CT-81 versus $81-81$ at the first testing trial $[F(1,76)=4.4, p<.05$, and $F(1,76)=5.3, p<.025$, respectively] and for $81-81$ at retraining $[F(1,76)=4.8$, $p<.05]$.

In short, a 9-sec ITI training failed to induce LTH in any of the two testing phases when the crabs were trained and tested with either the same or different trial spacings; however, a 27- or an 81-sec ITI training produced LTH at both testing phases when the same trial spacing was used at both sessions or only at the first testing trial when the animals were trained and tested with different ITIs. Interestingly, ongoing experiments at our laboratory are showing that 30 trials with an ITI slightly shorter than $27 \mathrm{sec}$ (i.e., $18 \mathrm{sec}$ ) fail to yield LTH, suggesting that a $27-\mathrm{sec}$ ITI might be a critical value of trial spacing. In other words, no LTH at retraining is shown either when the trial spacing at training is different from that at testing or when the trial spacing at training is shorter than $27 \mathrm{sec}$.

From these findings, it seems plausible that an increasing length of the ITI at training induces an increasing expression of LTH at testing - a conclusion essentially in keeping with results obtained in several independent laboratories with highly dissimilar preparations (Carew et al., 1972; M. Davis, 1970; File, 1973; Marlin \& Miller, 1981). However, it might be argued that crabs trained with a short ITI (e.g., $9 \mathrm{sec}$ ) fail to acquire LTH not because of the brief ITI but because of the large extension of the contextual phase $(36 \mathrm{~min})$ that precedes the iterative stimulation (Table 3) - that is, because of a likely latent inhibition effect.

To test whether or not this alternative explanation is attainable, another experiment was performed in the present series, consisting of four groups: CT-9, 9-9, (AD)CT-9, and (AD) 9-9. The two former groups were as above (CT-9 and 9-9), but the two additional ones differed in the extension of their phases during the training session; (AD)CT9 had only a 9-min contextual phase, and (AD) 9-9 had only a 9-min stimulation phase (Table 4).

Figure 3 presents the response-trial curves corresponding to the testing session of each trained group compared with that of its respective control group. Planned comparisons revealed no significant difference for any contrast; that is, for CT-9 versus 9-9 for (AD)CT-9 versus (AD) 9-9, or between controls. Thus, the crabs failed to acquire LTH with a 9-sec ITI at training in spite of eliminating the preexposure to the context in the trained group. It is worthwhile to note, however, that this result is not irreconcilable to the view that LTH can be impaired by the classical conditioning procedure of latent inhibition, since such an effect was found with $12 \mathrm{~h}$ of pretraining exposure to the actometer (Tomsic, Pedreira, Romano, Hermitte, \& Maldonado, in press).

Results from this section (Figure 2) show that the crabs trained and tested with an $81-$ or a 27 -sec ITI exhibited LTH at retraining, but not those trained with an 81 - or a 
A)

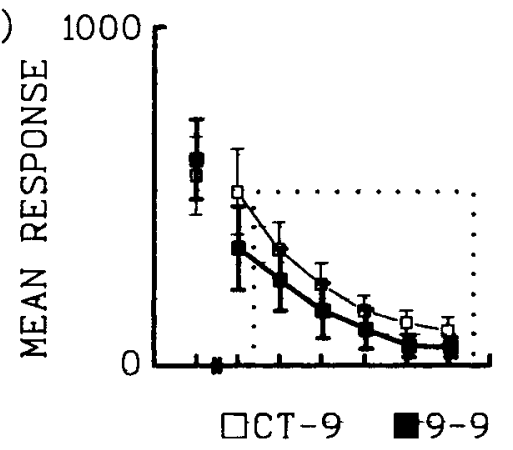

B)

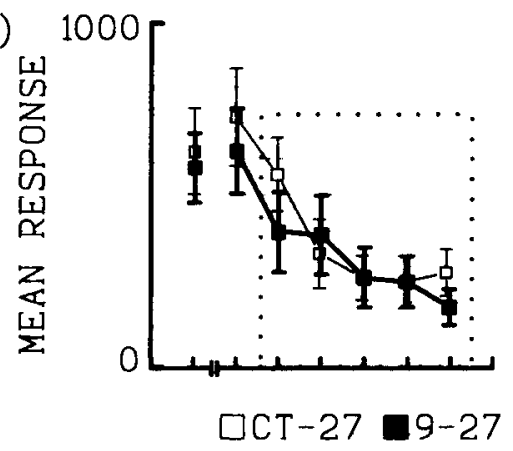

C)

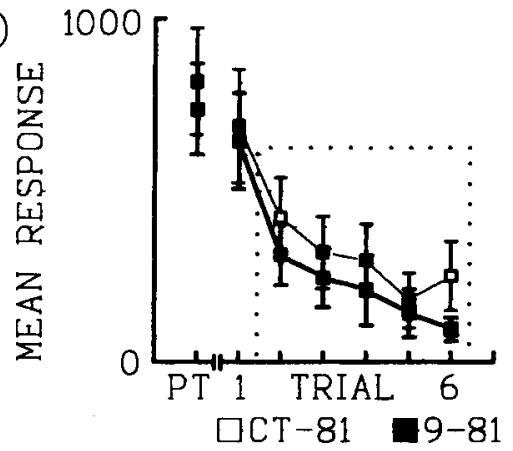

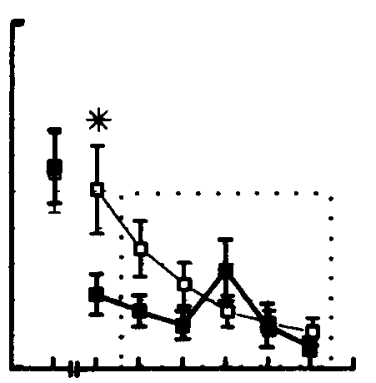

$\square$ CT $-9 \quad \mathbf{\square} 27-9$
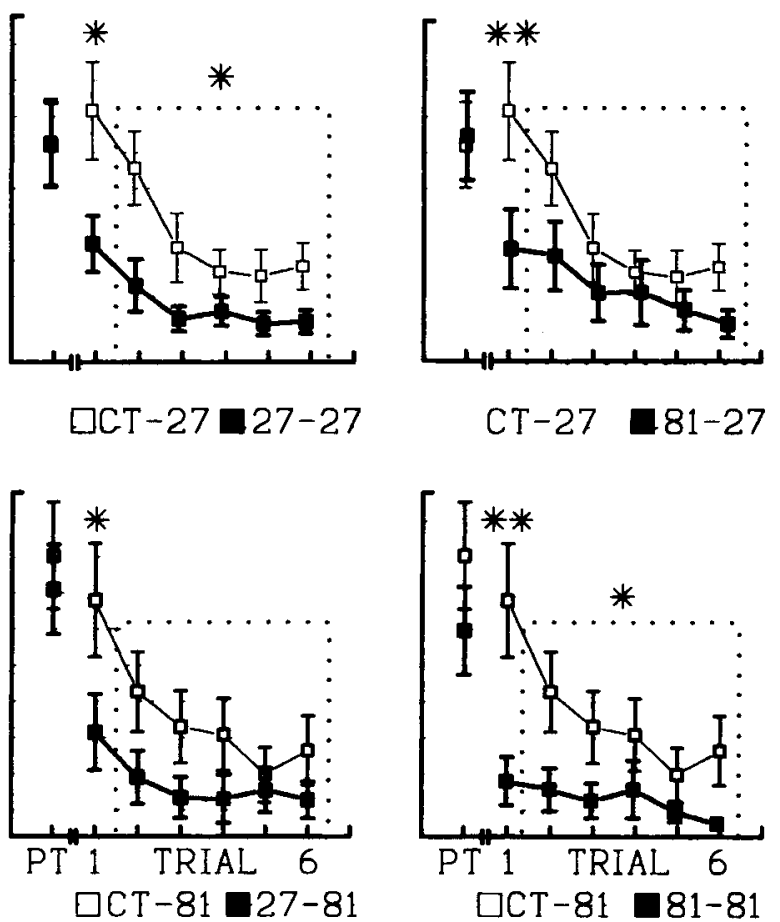
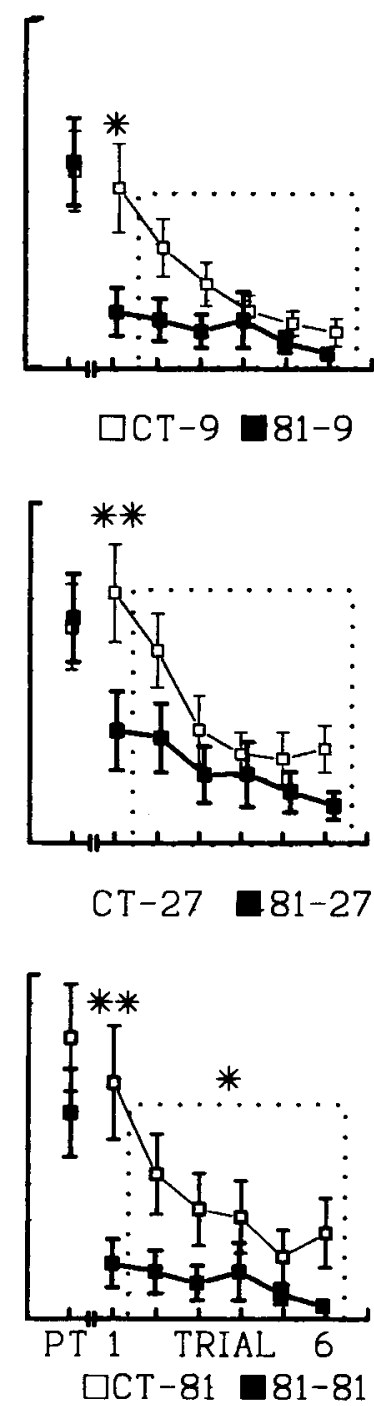

Figure 2. Effect of different lengths of intertrial interval, with the same number of training trials (30), on LTH. Graphs A-C: Results at testing. (A) Experiment 1, testing with 9 sec; left panel, training with 9-sec ITI; middle panel, training with 27-sec ITI; right panel, training with 81-sec ITI. (B) Experiment 2, testing with 27 sec; left panel, training with 9-sec ITI; middle panel, training with 27-sec ITI; right panel, training with 81-sec ITI. (C) Experiment 3, testing with 81 sec; left panel, training with 9-sec ITI; middle panel, training with 27-sec ITI; right panel, training with 81-sec ITI. ${ }^{*} p<.05$. ${ }^{* *} p<.025$ (significance level for CT-27 vs. 27-27; see text). Other symbols as in Figure 1. Results corresponding to the control group (CT) of each experiment are shown in the respective three row panels.

Table 4

Protocol for Alternative Experiment in the Second Series of Experiments

\begin{tabular}{|c|c|c|c|c|c|}
\hline \multirow[b]{2}{*}{$\begin{array}{l}\text { Group } \\
\text { Name }\end{array}$} & \multirow[b]{2}{*}{$\begin{array}{c}\text { Training } \\
\text { Trials }\end{array}$} & \multirow[b]{2}{*}{$\begin{array}{l}\text { Training } \\
\text { ITI (sec) }\end{array}$} & \multicolumn{2}{|c|}{ Training Session } & \multirow[b]{2}{*}{$\begin{array}{l}\text { Testing } \\
\text { ITI (sec) }\end{array}$} \\
\hline & & & $\begin{array}{l}\text { Contextual } \\
\text { Phase (min) }\end{array}$ & $\begin{array}{l}\text { Stimulation } \\
\text { Phase (min) }\end{array}$ & \\
\hline CT-9 & - & - & 45 & 0 & 9 \\
\hline $9-9$ & 30 & 9 & 36 & 9 & 9 \\
\hline (AD)CT-9 & - & - & 9 & 0 & 9 \\
\hline (AD) 9-9 & 30 & 9 & 0 & 9 & 9 \\
\hline
\end{tabular}



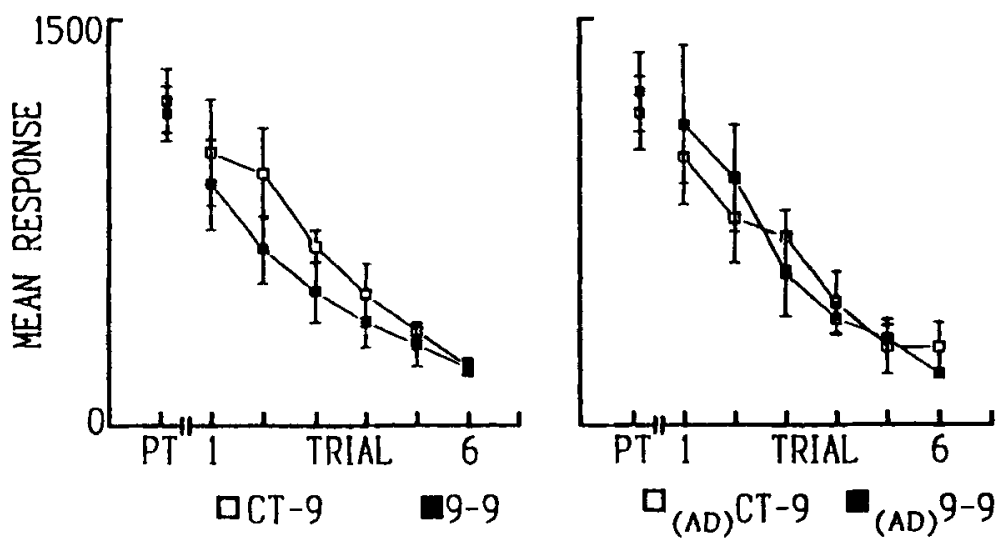

Figure 3: Evaluation of latent inhibition for the 9-sec ITI groups. Left panel, testing performance of groups CT-9 and 9-9 (as those of Figure 2B, left panel); right panel, testing performance of (AD)CT-9 (9 min of contextual phase at the training session) and (AD)9-9 (9 min of stimulation phase at the training session). Symbols as in Figure 1.

27-sec ITI and tested with a different ITI, thus hinting at the possibility that LTH is trial-spacing-specific at least within this range of ITIs.

Experiments in the next section were aimed at reexamining this issue but using longer ITIs (i.e., excluding the critical 27-sec ITI).

\section{Third Series of Experiments}

LTH at retraining is trial-spacing-specific within a range of intermediate ITIs. To demonstrate that LTH is trial-spacing-specific, it should be necessary to prove that memory retention at retraining shown when there is ITI congruity between sessions vanishes if the training or testing ITI shifts toward either longer or shorter values- - that is, toward stronger or weaker training or retraining.

For this purpose, ITIs of 135 and $45 \mathrm{sec}$ were chosen, with a range that included an ITI of $81 \mathrm{sec}$ and kept a relation of three times between extremes equal to that between 81 and $27 \mathrm{sec}$ of the series of experiments in the previous section. Two experiments were conducted, each comprising three groups: CT-45, 45-45, and 135-45 for Experiment 1, and CT-135, 45-135, and 135-135 for Experiment 2 . The training session lasted $72 \mathrm{~min}$ in the three groups of each experiment, and, as a consequence, the length of the training contextual and stimulation phases was different for each group (Table 5). The crabs of each experiment came from different captures.

The planned comparisons (Figure 4) showed a significant difference both at the initial testing phase and at the retraining phase between groups that were trained and evaluated with the same trial spacing: CT- 45 versus $45-45$ [Figure 4A left panel, $F(1,76)=6.2, p<.025$, for the first trial; $F(1,76)=9.8, p<.005$, for retraining] and CT-135 versus 135-135 [Figure 4B left panel, $F(1,76)=5.6$, $p<.025$, for first trial; $F(1,76)=7.4, p<.01$, for retraining]. In contrast, when ITI was shifted from training to testing, retention appeared only in the first testing trial: CT45 versus $135-45$ [Figure $4 \mathrm{~A}$ right panel, $F(1,76)=5.6$, $p<.025$ ] and CT-135 versus 45-135 [Figure 4B right panel, $F(1,76)=5.2, p<.025]$. In order to compare the performances of the trained groups at retraining in each experiment (i.e., $45-45$ vs. $135-45$, and $135-135$ vs. 45 135), two $2 \times 5$ ANOVAs (mixed repeated measure) were performed separately on scores of the five-trial block (trials 2-6) of each experiment, revealing a significant mean effect between groups [Experiment $1, F(1,38)=4.4$, $p<.05$; Experiment $2, F(1,38)=8.8, p<.005]$ and between trials [Experiment $1, F(4,152)=2.8, p<.025$; Experiment $2, F(4,152)=4.4, p<.05$ ] but not a significant group $\times$ trial interaction. An overall two-factor ANOVA

Table 5

Protocol for the Third Series of Experiments

\begin{tabular}{ccccccc}
\hline & & & & \multicolumn{2}{c}{ Training Session (72 min) } \\
\cline { 5 - 6 } Experiment & $\begin{array}{c}\text { Group } \\
\text { Name }\end{array}$ & $\begin{array}{c}\text { Training } \\
\text { Trials }\end{array}$ & $\begin{array}{c}\text { Training } \\
\text { ITI (sec) }\end{array}$ & $\begin{array}{c}\text { Contextual } \\
\text { Phase (min) }\end{array}$ & $\begin{array}{c}\text { Stimulation } \\
\text { Phase (min) }\end{array}$ & $\begin{array}{c}\text { Testing } \\
\text { ITI (sec) }\end{array}$ \\
\hline \multirow{2}{*}{1} & CT-45 & - & - & 72 & 0 & 45 \\
& $45-45$ & 30 & 45 & 45 & 27 & 45 \\
2 & $135-45$ & 30 & 135 & 0 & 72 & 45 \\
2 & CT-135 & - & - & 72 & 0 & 135 \\
& $45-135$ & 30 & 45 & 45 & 27 & 135 \\
& $135-135$ & 30 & 135 & 0 & 72 & 135 \\
\hline
\end{tabular}



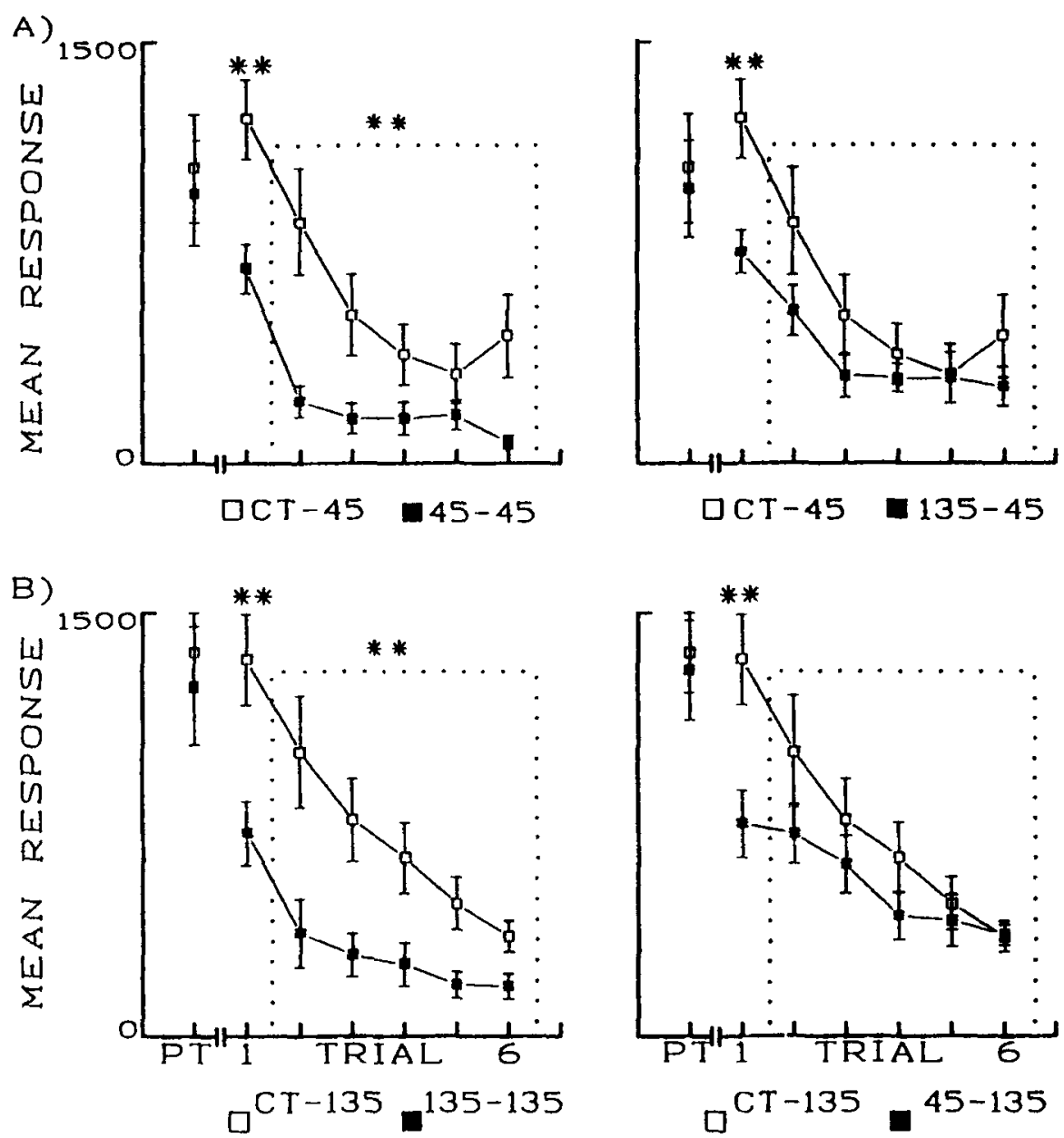

Figure 4. Trial-spacing specificity in the retraining phase. (A) Testing with 45 sec. (B) Testing with $135 \mathrm{sec}$. Symbols as in Figure 1. Results corresponding to the control group (CT) of each experiment are shown in the respective two row panels.

on data from trained groups of both experiments revealed no effect of training, a significant effect of training $[F(1,76)$ $=4.9, p<.05]$, and a significant interaction between training and retraining $(F(1,76)=11.0, p<.005)$. Thus, the cross-experiment comparison revealed a significant effect of ITI congruity between sessions. The reliable difference between marginal means of retraining reflects the fact that the overall level of responding in Experiment 2 was higher than that in Experiment 1 at both phases of testing.

Thus, a training-to-testing ITI shift seems to impair memory retention at the late phase of testing, suggesting that LTH at retraining would be trial-spacing-specific, at least within the range of the intermediate values of ITIs used here (between 27 and $135 \mathrm{sec}$ ) and when a relation of three times between intervals was kept. An alternative explanation in terms of difference in strength of retraining is implausible, since impairment due to the ITI shift occurs regardless of the length of the ITIs.

\section{Fourth Series of Experiments}

LTH at different phases of testing depends differentially on spaced training. During the previous sections, the effect of a decreasing series of training ITIs $(171,135,81,45,27$, and $9 \mathrm{sec})$ on LTH at both phases of testing was explored, keeping constant the number of

Table 6

Protocol for One Experiment in the Fourth Series of Experiments

\begin{tabular}{|c|c|c|c|c|c|}
\hline \multirow[b]{2}{*}{$\begin{array}{l}\text { Group } \\
\text { Name }\end{array}$} & \multirow[b]{2}{*}{$\begin{array}{c}\text { Training } \\
\text { Trials }\end{array}$} & \multirow[b]{2}{*}{$\begin{array}{l}\text { Training } \\
\text { ITI }(\mathrm{sec})\end{array}$} & \multicolumn{2}{|c|}{ Training Session } & \multirow[b]{2}{*}{$\begin{array}{c}\text { Testing } \\
\text { ITI }(\mathrm{sec})\end{array}$} \\
\hline & & & $\begin{array}{l}\text { Contextual } \\
\text { Phase (min) }\end{array}$ & $\begin{array}{l}\text { Stimulation } \\
\text { Phase (min) }\end{array}$ & \\
\hline$(60)$ CT-9 & - & 一 & 18 & 0 & 9 \\
\hline$(60) 27-27$ & 60 & 9 & 0 & 18 & 9 \\
\hline
\end{tabular}




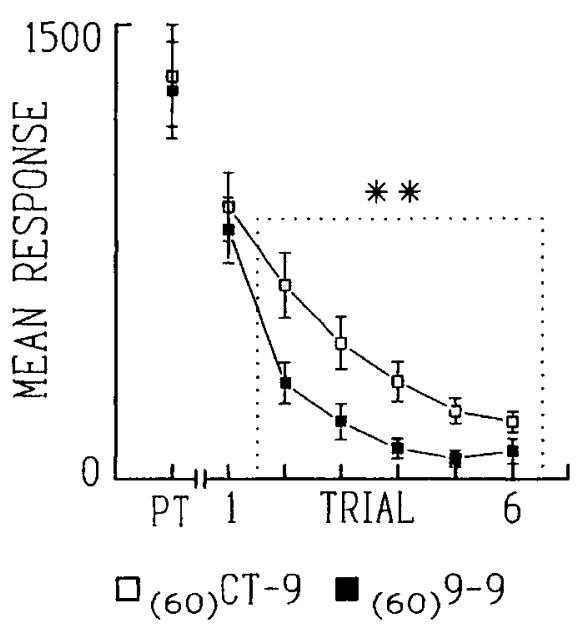

Figure 5. LTH at the retraining phase depends on the amount of training. Testing performance after 60 training trials. ITI = 9 sec, for both training and testing. Symbols as in Figure 1. training trials ( 30 trials). A general conclusion might be drawn from these results when the analysis is confined to experiments with the same ITI at both sessions. Specifically, if the training ITI is equal to or longer than $27 \mathrm{sec}$, LTH is expressed at both testing phases; however, if it is reduced to $9 \mathrm{sec}$, the strong training protocol fails to induce LTH at both testing phases. At this junction, a question seems necessary: Is it possible to offset a short ITI by increasing the number of training trials and thus obtaining LTH? Two lines of experiments were conducted aimed at answering this question.

The first step in this analysis was to investigate if LTH could also be produced with a 9-sec ITI training by increasing the number of training trials. The experiment included two groups: (60)9-9 and (60)CT-9 (Table 6). Results are displayed in Figure 5. A $t$ test on testing data failed to disclose a significant difference between control and trained groups at first trial, but these groups differed reliably at retraining $[F(1,38)=8.5, p<.005]$.
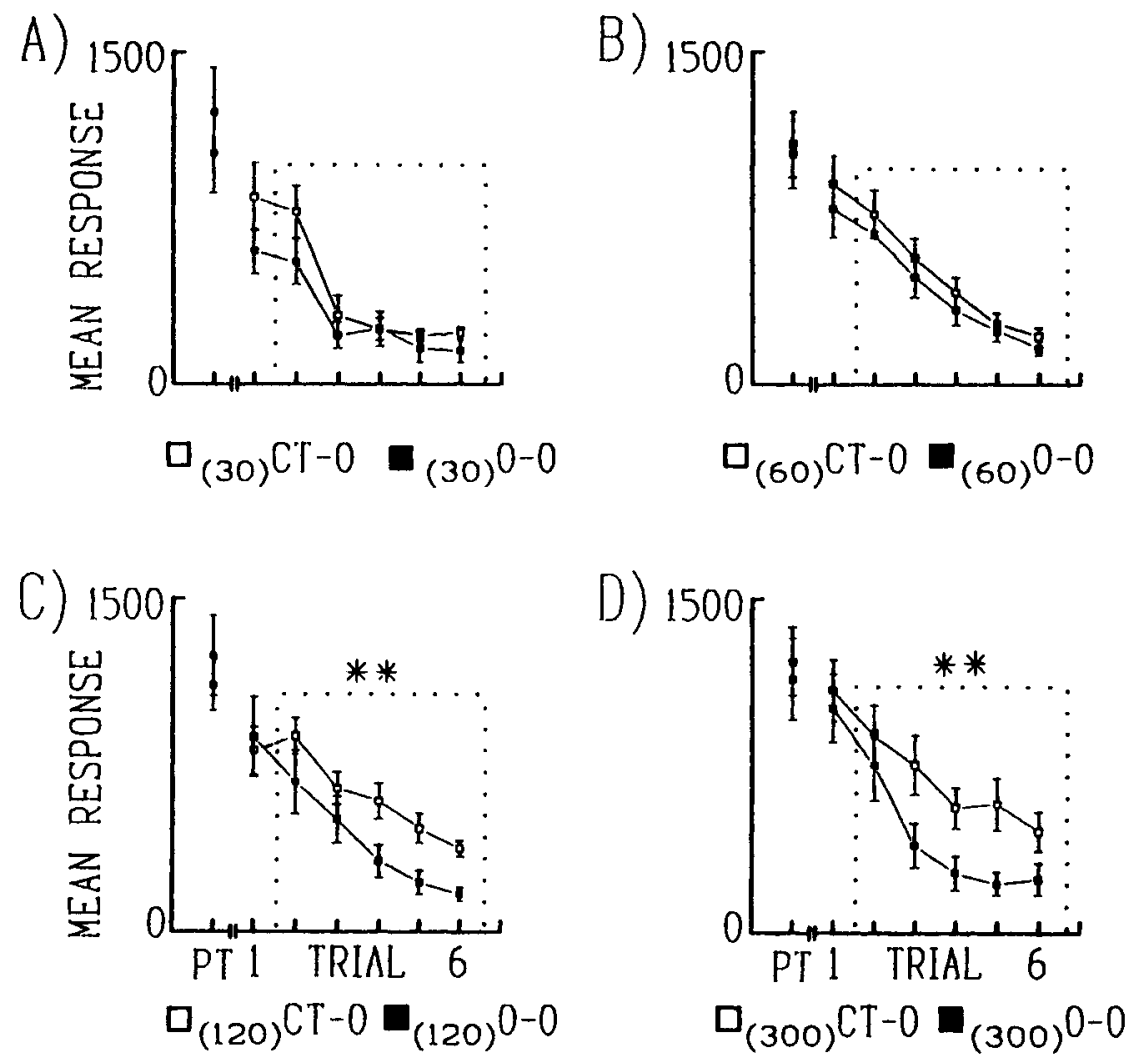

Figure 6. LTH at the retraining phase depends on the amount of training. Graphs A-C: testing performances after different number of training trials. ITI $=0 \mathrm{sec}$ for both training and testing. (A) 30 training trials: (30)CT-0 = control; (30)O-O = trained group. (B) 60 training trials: (60)CT-0 = control; (60)0-0 = trained group. (C) 120 training trials: $(120) C T-0=$ control; (120)0-0 = trained group. (D) 300 training trials: $(300) C T-0=$ control; $(300) 0-0=$ trained group. Symbols as in Figure 1. 
Table 7

Protocol for Four Experiments in the Fourth Series of Experiments

\begin{tabular}{|c|c|c|c|c|c|c|}
\hline \multirow[b]{2}{*}{ Experiment } & \multirow[b]{2}{*}{$\begin{array}{l}\text { Group } \\
\text { Name }\end{array}$} & \multirow[b]{2}{*}{$\begin{array}{c}\text { Training } \\
\text { Trials }\end{array}$} & \multirow[b]{2}{*}{$\begin{array}{l}\text { Training } \\
\text { ITI (sec) }\end{array}$} & \multicolumn{2}{|c|}{ Training Session } & \multirow[b]{2}{*}{$\begin{array}{l}\text { Testing } \\
\text { ITI (sec) }\end{array}$} \\
\hline & & & & $\begin{array}{l}\text { Contextual } \\
\text { Phase (min) }\end{array}$ & $\begin{array}{l}\text { Stimulation } \\
\text { Phase (min) }\end{array}$ & \\
\hline \multirow[t]{2}{*}{1} & (30)CT-0 & - & - & 4.5 & 0 & 0 \\
\hline & $(30) 0-0)$ & 30 & 0 & 0 & 4.5 & 0 \\
\hline \multirow[t]{2}{*}{2} & (60)CT-0 & - & - & 9 & 0 & 0 \\
\hline & $(60) 0-0$ & 60 & 0 & 0 & 9 & 0 \\
\hline \multirow[t]{2}{*}{3} & (120)CT-0 & - & - & 18 & 0 & 0 \\
\hline & $(120) 0-0$ & 120 & 0 & 0 & 18 & 0 \\
\hline \multirow[t]{2}{*}{4} & (300)СТ-0 & - & - & 45 & 0 & 0 \\
\hline & $(300) 0-0$ & 300 & 0 & 0 & 45 & 0 \\
\hline
\end{tabular}

This result suggests the possibility that any attempt to yield LTH at first trial would meet with failure if training was given without ITI, which, in turn, suggests that retention at the initial testing phase would necessarily call for a significant trial spacing. For the purpose of testing this assumption, another series of four experiments was performed using no ITI-that is, a strict massed training. Each experiment included one trained group that received $30,60,120$, or 300 trials in the training session, with a 0 -sec ITI both in training and testing, and the respective control group with a 0 -sec ITI at testing: (30)CT-0 and (30)0-0 in Experiment 1; (60)CT-0 and (60)0-0 in Experiment 2; (120) CT-0 and (120)0-0 in Experiment 3; and (300)CT-0 and (300)0-0 in Experiment 4 (Table 7). The crabs from different experiments came from different captures.

Figure 6 exhibits results corresponding to the testing session. As expected, no statistical difference ( $t$ test, $p>.05$ ) was found between (30)CT-0 and (30)0-0 either at first trial or at retraining (Figure 6A). LTH was not yielded when the number of training trials was duplicated (Figure 6B); however, when training was increased 4 or 10 times, a significant difference for CT versus TR was found, though confined to the retraining phase $[F(38)=$ $5.3, p<.025$, for $(120)$ CT- 0 vs. (120)0-0, Figure $6 \mathrm{C}$; $F(38)=5.2, p<.025$, for (300)CT-0 vs. (300)0-0, Figure $6 \mathrm{D}]$.

It is worth noting that 300 trials with 0 -sec ITIs entail a continuous stimulation during $45 \mathrm{~min}$ (Table 7). This stimulation interval is equal to that of 15 training trials with 171-sec ITIs (Table 2), but results were contrasting: In one case, a robust retention at both testing phases was obtained (Figure 1B), whereas, in the other, LTH was expressed only at retraining (Figure 6D).

A conclusion may be drawn from these results: LTH at different phases of testing depends differentially on spaced training. Massed training produced LTH at retraining but not at the initial testing phase, though the number of training trials was largely increased; in contrast, spaced training yielded LTH at first trial and also at retraining when enough training trials were given.

\section{DISCUSSION}

A salient result of this work concerns the relation between spaced or massed training and the strength of LTH at two different phases of testing. Massed training produces LTH only at retraining - that is, it fails to be expressed at the initial phase in spite of the fact that an extremely large amount of trials were given during the training session. Therefore, the distinction between two memory components in LTH seems plausible: a component yielded by massed training and expressed only at retraining, and another one produced only by spaced training and expressed at both initial testing phase and retraining.

However, an alternative explanation may be offered. Namely, it may be argued that massed training results in the aftereffects of recent stimulus presentations that would be a critical part of the habituation context. On the first trial of testing, that stimulus component would be missing; however, retraining would reinstate its presence and might therefore lead to exhibition of LTH produced by massed training. In other words, the same mechanism may be acting after either massed or spaced training, contributing to performance differences.

We cannot with confidence decide, on the basis of the results of the present study, between the two explanations above. However, preliminary results from ongoing studies at our laboratory are indicating that different behavioral and pharmacological treatments affect difierently the two putative components of LTH. Thus, LTH after spaced, but not after massed, training is affected either by cycloheximide or by a training-to-testing contextual shift. Besides, 300 trials without ITIs produce LTH during retraining even if a 171-sec spaced testing is used, thus contrasting with the trial-spacing specificity suggested for LTH after spaced training. The latter result is at variance with the alternative explanation, since retraining with a $171-\mathrm{sec}$ ITI could not evoke the aftereffects of a recent massed stimulation. If these preliminary findings were confirmed, there would be good grounds to support the idea that two different mechanisms are subserving two memory components of Chasmagnathus LTH.

At this juncture, it is worth noting that the presence of two putative memory components in Chasmagnathus LTH is absent in other related crustaceans, as was confirmed by results obtained from comparative studies on learning ability in crabs. In fact, LTH was also studied in Pachygrapsus marmoratus, a crab collected in the bay of Naples, Italy, using the same experimental set-up and experimental protocols. Pachygrapsus and Chasmagnathus 
are closely related in phylogeny, resembling each other in size and life span, and both are semiterrestrial runners that display a fast escape response to a visual danger stimulus (Tomsic et al., 1993). However, they diverge widely in ecology and in the expression of LTH when tested $24 \mathrm{~h}$ after a strong spaced training. LTH in Chasmagnathus is expressed at both the initial phase and the restraining phase of testing, whereas LTH in Pahygrapsus is expressed at retraining only. Therefore, the isolated retraining component could be shown either by giving a spaced or massed training to a crab that is unable to exhibit LTH at initial testing or by giving massed training to a crab that can exhibit LTH at initial testing after spaced training.

The idea that crabs' LTH has two discernible memory components grounded on different stimulus requirements is in keeping with the habituated model proposed by Dafters (Dafters, Odber, \& Miller, 1988) and with results obtained from work on different types of learning in other organisms. Thus, as cited in the introduction, a distinction between two memory components has been proposed concerning odor avoidance conditioning in Drosophila (Tully et al., 1994)-namely, an anesthesia-resistant memory produced by either massed or spaced training, insensitive to cycloheximide and disruptable by the radish singlegene mutation (Folkers, Drain, \& Quinn, 1993), and a long-term memory yielded only by spaced training, disruptable by cycloheximide but not by the radish. Similarly, a different stimulus requirement was one of the grounds for distinguishing between two modalities of an associative learning in Drosophila - namely, dishabituation induced by a weak stimulus and sensitization by a strong stimulus-likely reflecting different underlying mechanisms (Marcus, Nolen, Rankin, \& Carew, 1988).

Another noticeable result of this study shows, in keeping with a previous finding from our laboratory (Lozada, 1993), that LTH retention is impaired when different ITIs are used at training and testing. An ITI shift diminishes or abolishes retention at retraining regardless of the direction of the shift, either toward longer or shorter intervals (third series of experiments). It is believed that animals are timing when the duration of an event serves as a discriminative stimulus for them (i.e., as a cue for responding one way rather than another; e.g., H. Davis \& Memmott, 1982; Meck \& Church, 1983). Accordingly, crabs may be able to time, indicating that the capacity of responding on the basis of temporal information is shared by very different animal species. This overspread capacity correlates well with the fact that stimuli in the environment rarely occur randomly and independently of each other. Rather, many aspects of the environment involve orderly patterns of stimulation (Domjan \& Burkhard, 1986).

\section{REFERENCES}

Applewhite, B. P., Gardner, F. T., \& Lapan, E. (1969). Physiology of habituation learning in a protozoan. Transactions of the New York Academy of Sciences, 31, 842-849.

Brunner, D., \& Maldonado, H. (1988). Habituation in the crab Chas- magnathus granulatus: Effect of morphine and naloxone. Journal of Comparative Physiology, 162, 687-694.

CAMpbell, B. A., \& Jaynes, J. (1966). Reinstatement. Psychological Review, 73, 478-480

Carew, T. J., Pinsker, H. M., \& Kandel, E. R. (1972). LTH of a defensive withdrawal response reflex in Aplysia. Science, 175, 451454.

Dafters, R. I., Odber, J., \& Miller, J. (1988). Associative and nonassociative tolerance to morphine: Support for a dual process of habituation model. Life Science, 42, 1897-1906.

DAvis, H., \& MEMMOTT, J. (1982). Counting behavior in anımals: A critical evaluation. Psychological Bulletin, 92, 547-571.

DAvis, M. (1970). Effects of interstimulus interval length and variability on startle response habituation in rat. Journal of Comparative \& Physiological Psychology, 72, 177-192.

DOMJAN, M., \& BURKHARD, B. (1986). The principles of learning and behavior (2nd ed.). Monterey, CA: Brooks/Cole.

FILE, S. E. (1973). Inter-stimulus interval length and the rate of behavioral habituation. Quarterly Journal of Experimental Psychology, 25, 360-367.

Folkers, E., Drain, P., \& QuinN, W. G. (1993). Radish, a Drosophila mutant deficient in consolidated memory. Proceedings of the National Academy of Sciences, 90, 8123-8127.

Frost, W. N., Castellucci, V. F., Hawkin, S. R. D., \& Kandel, E. R, (1985). Monosynaptic connections from sensory neurons of the gill and siphon withdrawal reflex in Aplysia participate in the storage of long-term memory and sensitization. Proceedings of the National Academy of Sciences, 82, 8266-8269.

Hintzman, D. L. (1974). Theoretical implications of the spacing effect. In R. L. Solso (Ed.), Theories in cognitive psychology: The Loyola Symposium (pp. 77-99). Hillsdale, NJ: Erlbaum.

HowelL, D. C. (1987). Statistical methods for psychology (2nd ed.). Boston: Duxbury.

LOZADA, M. (1993). Habituación a largo termino y especificidad del estimulo en el cangrejo Chasmagnathus granulatus [Stimulusspecificity of long-term habituation in the crab Chasmagnathus granulatus]. Unpublished doctoral dissertation, Buenos Aires University.

Lozada, M., Romano, A., \& Mal.Donado, H. (1990). Long-term habituation to a danger stimulus in the crab Chasmagnathus granulatus. Physiology \& Behavior, 47, 35-41.

Marcus, E. A., Nolen, T. G., Rankin, C. H., \& Carew, T. J. (1988). Behavioral dissociation of dishabituation, sensitization, and inhibition in Aplysia. Science, 241, 210-213

Marlin, N. A., \& Miller, R. R. (1981). Association to contextual stimuli as a determinant of long term habituation. Journal of Experimental Psychology: Animal Behavior Processes, 7, 313-333.

MECK, W. H., \& CHURCH, R. M. (1983). A mode control model of counting and timing processes. Journal of Experimental Psychology. Animal Behavior Processes, 9, 320-334.

MENZEL, R. (1996). Spaced rather than massed conditioning leads to protein synthesis dependent long-term memory in honeybees. Society for Neuroscience Abstracts, 22, 1405.

Menzel, R., Gaio, U. C., Gerberding, M., Nemrava, E. A., \& WittSTOCK, S. (1993). Formation of long-term olfactory memory in honeybees does not require protein synthesis. Naturwissenschaften, 80, 380382 .

Pedreira, M. E., Dimant, B., \& Maldonado, H. (1996). Inhibitors of protein and RNA synthesis block context memory and long-term habituation in the crab Chasmagnathus. Pharmacology, Biochemistry \& Behavior, 54, 611-617.

Pedreira, M. E., Dimant, B., Tomsic, D., Quesada-Allue, L. A., \& Maldonado, H. (1995). Cycloheximide inhibits context memory and long-term habituation in the crab Chasmagnathus. Pharmacology Biochemistry \& Behavior, 52, 385-395.

PEEKE, H. V. S., \& VFNo, A. (1976). Stımulus specificity of habituated aggression in the three-spined stıcklebacks Gasterosteus acualeatus Zeitschrift für Tierpsychologie, 40, 53-58.

Rescorl.A, R. A. (1988). Behavioral studies of Pavlovian conditioning. Annual Review of Neuroscience, 11,320-352.

Romano, A., Delorenzi, A., Pedreira, M. E., Tomsic, D., \& Maldon- 
ADO, H. (1996). Acute administration of a permeant analog of cAMP and a phosphodiesterase inhibitor improve long-term habituation in the crab Chasmagnathus. Behavioural Brain Research, 75, 119-125.

Romano, A., Locatelli, F., Delorenzi, A., Pedreira, M. E., \& MalDONADO, H. (1996). Effects of activation and inhibition of cAMPdependent protein kinase on long-term habituation in the crab Chasmagnathus. Brain Research, 735, 131-140.

Romano, A., Lozada, M., \& MaLdonado, H. (1990). Effect of naloxone pretreatment on habituation in the crab Chasmagnathus granulatus, Behavioral \& Neural Biology, 53, 113-122.

Rosenthal, R., \& Rosnow, R. L. (1985). Contrast analysis: Focused comparisons in the analysis of variance. Cambridge: Cambridge University Press.

Saraco, M., \& Maldonado, H. (1995). Ethanol affects context memory and long-term habituation in the crab Chasmagnathus. Pharmacology, Biochemistry \& Behavior, 51, 223-229.

Thompson, R. F., Groves, P. M., Teyler, T. J., \& Roemer, R. H.
(1973). Habituation: A model phenomenon for the study of neural substrates of behavior. In H. V. S. Peeke \& M. J. Herz (Eds.), Habituation (Vol. 1., pp. 239-271). New York: Academic Press.

Tomsic, D., Maldonado, H., \& Rakitin, A. (1991). Morphine and GABA: Effects on perception, escape response and long-term habituation to a danger stimulus in the crab Chasmagnathus. Brain Research Bulletin, 26, 699-706.

Tomsic, D., Massoni, V., \& Maldonado, H. (1993). Habituation to danger stimulus in two semiterrestrial crabs: Ontogenic, ecological and opioids modulation correlates. Journal of Comparative Physiology, 173, 621-633.

Tomsic, D., Pedreira, M. E., Romano, A., Hermitte, G., \& MaldonADO, H. (in press). Context-US association as a determinant of longterm habituation in the crab Chasmagnathus. Animal Learning \& Behavior.

Tully, T., Preat, T., Boyton, S. C., \& Del Vecchro, M. (1994). Genetic dissection of consolidated memory in Drosophila. Cell, 79, 35-47.

(Manuscript received February 26, 1996;

revision accepted for publication June 20, 1997.) 